\title{
La interpretación judicial: dificultades de la traducción oral de las sentencias del español al inglés
}

\author{
(Court interpreting: difficulties presented by the oral \\ translation of sentences from Spanish into English)
}

\author{
VERÓNICA PÉREZ GUARNIERI \\ Universidad del Salvador - Argentina
}

Fecha de recepción: 23 de agosto de 2013

Fecha de aceptación: 30 de septiembre de 2013

Resumen: En este trabajo se abordan las dificultades a las que se enfrentan los intérpretes jurados que deben actuar en fueros donde se impone la oralidad. De ésta, la más omnipresente y, quizás, la más difícil de afrontar es la velocidad a la que hablan o leen los magistrados y otros funcionarios del Poder Judicial. Se trata de establecer las ventajas de contar con el texto de referencia por adelantado para prepararlo, lo que impacta positivamente en la calidad de la traducción oral. El fin último es encontrar técnicas utilizadas en la formación de intérpretes que pudieran auxiliar al intérprete jurado cuando. Para ellos se han tomado muestras de traducción oral del mismo texto en diferentes circunstancias.

Palabras clave: Intérprete jurado, Traducción oral inglés-español, Capacitación de intérpretes.

Abstract: This article deals with the difficulties faced by court interpreters. These are many but the ubiquitous and most difficult to deal with is perhaps the speed at which court officers speak and read. The aim is establishing the advantages of having the text in question in advance to prepare it, which positively impacts on the quality of the oral translation. The ultimate goal is to find techniques used in training interpreters to facilitate the job of court interpreters and enhance quality of the output. To this end, I have taken samples of oral translations of the same text in different circumstances.

Key words: Court interpreter, Oral translation Spanish-English, Interpreter training. 


\section{INTRODUCCIÓN}

En la República Argentina, el traductor público es el profesional universitario cuya competencia, de conformidad con la Ley 20.305 , es la traducción de todo documento en idioma extranjero o que deba traducirse a otro idioma que no sea el español y que deba presentarse ante reparticiones, entidades u organismos públicos. Es el único profesional del campo de la traducción y la interpretación habilitado para darle validez legal a una traducción mediante su firma y sello. Este carácter fedatario le otorga una marca distintiva que hace imprescindible su intervención cuando se busca garantizar seguridad jurídica en las diferentes transacciones.

El traductor público, en calidad de perito auxiliar de la justicia, puede actuar como intérprete en juzgados y tribunales cuando es necesario traducir oralmente contenidos de una lengua a otra, convirtiéndose, de este modo, en el único profesional que puede ejercer de intérprete y traductor en una sede judicial.

Igualmente, en el ámbito privado, sus servicios pueden ser solicitados para la traducción de material escrito o para actuar como intérprete en situaciones que requieran responsabilidad profesional y un alto grado de capacitación y dominio de destrezas interpretativas, tales como las que requieren las mediaciones, los arbitrajes, las declaraciones extrajudiciales, etc.

Si el traductor de cualquier especialización debe ofrecer siempre una rigurosa precisión lingüística, el traductor e intérprete jurado debe ser aún más preciso por el rol que desempeña no solo como nexo insustituible de comunicación, sino como fedatario de la fe pública. Por ello, el ejercicio de la profesión de traductor público exige una mayor especialización y un profundo conocimiento y actualización, tanto de los idiomas de trabajo como del conocimiento general.

Numerosos traductores en Argentina se forman en la disciplina de interpretación y se desenvuelven, también, como intérpretes de conferencia, en la modalidad consecutiva o simultánea. Sin embargo, muchos de ellos deciden ejercer de intérprete auxiliar de la justicia pese a no contar con las destrezas necesarias para desempeñar esta labor.

Como profesional de la interpretación judicial, a lo largo de mi trayectoria, he detectado las innumerables dificultades que entraña la traducción oral, en especial, la traducción de sentencias del español al inglés. En mi afán de advertir y concienciar sobre estas dificultades, me embarqué en la tarea de investigar técnicas utilizadas en la formación de intérpretes que pudieran auxiliar al traductor jurado cuando debe desempeñarse en la oralidad. Las dificultades a las que se enfrentan los 
intérpretes jurados que deben actuar en fueros donde se impone la oralidad son muchas, pero la sempiterna y, quizás, la más difícil de barrenar es la velocidad a la que hablan y leen los magistrados y otros funcionarios del Poder Judicial.

1. LA INTERPRETACIÓN JUDICIAL. DEFINICIÓN, CARACTERÍSTICAS Y FUNCIONES

Es importante contextualizar el presente trabajo analizando las similitudes y diferencias entre los sistemas jurídicos involucrados en el caso que nos ocupa: lengua A (español) y lengua B (inglés). El objetivo es poder encontrar los equivalentes de las instituciones en el proceso de traducción entre los dos grupos de derechos principales del mundo occidental contemporáneo: la familia romano-germánica, base del derecho europeo, y la familia del "Common Law".

\subsection{Derecho romano-germánico}

La primera familia de derechos que trataré -por adscribirse a ésta la sentencia que analizaremos posteriormente- es la familia romanogermánica, que comprende los países cuyo sistema de derecho se formó sobre la base del sistema de derecho romano. También denominado Derecho Continental para diferenciarlo del "Common Law" o derecho propio de las Islas Británicas (fuera del continente). En este sistema de derecho se atribuye a la ley una función preponderante; los diferentes países pertenecientes a esta familia han adoptado la fórmula de "códigos" a partir del código civil que sirve de referencia para codificar los demás campos del derecho (penal, comercial, aeronáutico, etc.). La familia del derecho romano-germánico nace en Europa y se fue desarrollando a través de la obra de las universidades europeas que se crearon desde el siglo XII, originando así una ciencia jurídica adecuada a las condiciones del mundo moderno. Como consecuencia de la colonización, la familia romanogermánica se expandió allende los mares, existiendo así un número infinito de territorios en los que tenía ámbito de aplicación, a pesar de la existencia de un sinfín de diferencias entre los sistemas de derecho miembro de la familia romano-germánica. En este sistema de derecho, las normas son dictadas por los poderes legislativo y ejecutivo, normas que interpreta y aplica el poder judicial, limitándose la jurisprudencia a la interpretación de la normativa vigente.

Dentro de este sistema jurídico se encuentra inserto el Tribunal Supremo con sede en Madrid. Se trata de un órgano jurisdiccional único en España, competente para actuar en todo el territorio nacional, y en los ámbitos civil, penal, contencioso-administrativo y social, salvo en materia de 
garantías y derechos constitucionales, cuya competencia corresponde al Tribunal Constitucional.

El accionar del Tribunal Supremo se explicita en el Artículo 123 de la Constitución Española (Boletín Oficial del Estado núm. 311, de 29 de diciembre de 1978: 29371):

1. El Tribunal Supremo, con jurisdicción en toda España, es el órgano jurisdiccional superior en todos los órdenes, salvo lo dispuesto en materia de garantías constitucionales.

2. El Presidente del Tribunal Supremo será nombrado por el Rey, a propuesta del Consejo General del Poder Judicial, en la forma que determine la ley.

El Tribunal Supremo es la cúpula del sistema de recursos, por lo que está en sus manos tender los puentes entre la jurisprudencia y la interpretación. Entre otros asuntos, decide respecto de los recursos de casación, revisión y otros extraordinarios, del enjuiciamiento de los miembros de altos órganos del Estado y de los procesos de declaración de ilegalización de partidos políticos. Es el tribunal de última instancia (final) en todos los casos y sus decisiones sólo pueden quedar sin efecto cuando el Tribunal Constitucional encuentra lesión de los derechos y libertades constitucionales. En todos los demás casos, no es posible recurrir una decisión firme del Tribunal Supremo. ${ }^{1}$

La sentencia analizada posteriormente llega al Tribunal Superior "por infracción de precepto constitucional, concretamente de los derechos fundamentales a la tutela judicial efectiva y a la presunción de inocencia", competencia comprendida en el Artículo 53 de la Constitución Española, así como a la Sala Segunda, por tratarse de una causa penal, competencia comprendida en el Artículo 57 Inciso 1 de la Constitución Española.

\subsection{El sistema jurídico inglés y el "Common Law" o Derecho Común}

El segundo sistema jurídico es el de la lengua B: el sistema del "Common Law" que puede traducirse literalmente como Derecho Común, aunque esta traducción no capta íntegramente el significado, por lo que se prefiere mantener el término "Common Law", que tiene sus orígenes en las costumbres medievales inglesas. Está formado, según René David (1968: 21), por los derechos "herederos del derecho romano, cuya evolución han

${ }^{1}$ Sitio oficial del Poder Judicial de España. Capítulo: Tribunal Supremo. Disponible en línea en: http://www.poderjudicial.es/cgpj/es/Poder_Judicial/Tribunal_Supremo

[Consultado el 2 de abril de 2013] 
completado"..."tanto más cuanto se han incorporado en ellos elementos procedentes de otros derechos".

En los Derechos de la familia romano-germánica los principios jurídicos siempre se han buscado en un cuerpo de normas preestablecido, denominado en la actualidad Corpus iuris civilis o códigos. En cambio, la obligación de atenerse a las normas elaboradas por los jueces (stare decisis) se encuentra en la base de todo sistema de Derecho jurisprudencial como el "Common Law". Este último es un derecho no escrito que, a diferencia del derecho continental romano-germánico no reconoce en la ley la fuente principal del derecho. Este sistema se aplica en los países anglosajones: Reino Unido, Irlanda, Canadá (salvo en Quebec, en el que solo se lo utiliza en materia penal), Estados Unidos (menos el estado de Luisiana), Nueva Zelanda, Australia, Sudáfrica, Hong Kong, la república de Singapur, Malasia y la India.

Así pues, en el contexto histórico de estos países se introduce un elemento nuevo: la jurisprudencia, compuesta por los precedentes, siendo estos las decisiones dictadas por los jueces de los tribunales superiores. El verdadero factor de unidad son los jueces, y la jurisprudencia es el instrumento principal que garantiza la tutela de las libertades. Para aplicar el derecho, los jueces se basan en fallos anteriores, llamados precedentes, que al repetirse en el tiempo se consolidan como costumbre, pasando a formar parte del derecho. La ventaja de este sistema es que los ciudadanos no quedan sujetos al capricho político del gobierno de turno que puede dictar normas legislativas coyunturales y oportunistas. Por otro lado, la responsabilidad de la equidad en la resolución de la causa queda en manos del Juez exclusivamente, perdiendo protagonismo el legislador.

En la práctica, no es un sistema sencillo, dado que hallar un precedente similar al caso del que se encarga el Juez puede convertirse en una gesta pantagruélica por la cantidad de casos acumulados desde épocas medievales hasta el presente. Hay recopilaciones de jurisprudencia como los "Law Reports" para facilitar la tarea judicial. El sistema del "Common Law" es inductivo por naturaleza porque el juez va desde el caso particular al precedente. Es importante notar que el precedente es vinculante para el Juez; es imposible fallar en un sentido diferente al indicado por el precedente aunque cada caso aportará peculiaridades, lo que garantiza la constante evolución de este sistema de derecho.

\subsection{Instituciones Procesales del "Common Law"}

La "Supreme Court of Judicature" tiene dos instancias: el "High Court of Justice" y la "Court of Appeal". Las causas son remitidas, en general, al 
"High Court of Justice", con instancia de revisión ante el "Court of Appeal". A su vez, el "High Court of Justice" está formado por tres divisiones: la "Queen's Bench Division", la "Chancery Division", y la "Probate, Divorce and Admiralty Division". Cada división es competente para entender de cualquier asunto, sin embargo, en la actualidad para agilizar los trámites se ha realizado una asignación sistemática de los casos.

Los casos son presentados en primera instancia a la resolución de un jurado de 12 miembros. Si el caso se eleva a la "Court of Appeal", entonces, fallan dos o tres jueces. Este Tribunal revisa todos los aspectos legales de las sentencias de los tribunales inferiores y nunca acepta por segunda vez las pruebas presentadas en el proceso, aunque puede estudiar pruebas adicionales dentro de límites estrictos (Zweigert: 2002). Contra el fallo en apelación puede entablarse un recurso extraordinario ante la "House of Lords".

Por lo general, el ciudadano inglés que se ve en la necesidad de participar en litigios civiles no inicia acciones ante el "High Court of Justice", ni mucho menos ante la "Court of Appeals", sino en los tribunales de primera instancia; a saber; de la jurisdicción penal, el "Magistrate's Court", y de la civil, los "County Courts". La jurisdicción de los primeros se concentra en el derecho penal, fuero que se ocupa de los delitos menores, infracciones e incidentes de tránsito. En el caso de los delitos penales graves, el tribunal competente será el "Crown Court". Los "County Courts" fueron creados para facilitar el acceso de las partes a la justicia a fin de dirimir con diligencia pleitos privados, ya que al pertenecer a la jurisdicción civil, se sobreentiende que trata de disputas, pleitos o litigios entre ciudadanos, y no entre ciudadanos y el estado, como sucede en el ámbito de derecho penal.

\subsection{Diferencias y similitudes generales entre sistemas}

A tenor de lo expuesto anteriormente, se puede concluir que el sistema del Derecho Continental (que se asienta en códigos) es diferente al sistema del "Common Law" en varios aspectos:

1) En el sistema de Derecho Continental el legislador es quien crea la ley. En el sistema del "Common Law" el juez es quien crea la ley mediante le recopilación de sentencias dictadas por los tribunales ingleses, denominas precedentes, y recogidas en los "Law Reports" o Repertorios de Jurisprudencia.

2) El sistema de Derecho Continental es un sistema lógico. Los abogados quieren saber qué dice el Código. El sistema del "Common Law" 
es un sistema de practicalidad. En este caso, los abogados quieren saber qué es lo que funciona.

3) En el sistema codificado todo está escrito. En el "Common Law" hay mucho que se intuye.

4) En el caso, entonces, del Derecho Continental la ley es permanente, escrita y el texto es importante. En cuanto al sistema del "Common Law", el Derecho cambia constantemente.

No se puede decir que ambos sistemas existen en forma pura. De hecho, en la mayoría de los países existe una combinación de ambos con prevalencia de uno sobre el otro.

He aquí las dificultades que comparten los traductores/intérpretes jurados que se ocupan de este campo del conocimiento. Deben poder moverse con holgura entre los sistemas jurídicos aplicables a las lenguas de las cuales y hacia las cuales traducen, además de conocer la instancia del proceso dentro del cual está insertada en su traducción.

\section{DIFICULTADES Y DIFERENCIAS TRADUCTOLÓGICAS ENTRE SENTENCIAS}

Con el fin de poner de manifiesto las dificultades de la interpretación de las sentencias en el binomio de lenguas inglés-español, hemos tomado una sentencia de un Tribunal español (Sentencia de Tribunal Supremo Sala $2^{\circ}$, de lo Penal, de 27 de diciembre, $n^{\circ} 1183 / 2010$ ) que fue traducida en tres ocasiones diferentes; la primera traducción, previa interpretación, se hizo por escrito, mientras que las otras dos solo se tradujeron a vista. En el primer caso, el traductor tuvo la posibilidad de acceder al texto con media hora de anticipación para prepararlo previa interpretación, y en los otros dos casos, los traductores tuvieron que enfrentarse a la interpretación sin haber leído el texto con anterioridad.

Por medio de este corpus trataré de reproducir algunos ejemplos extraídos de las sentencias que ilustran cómo la traducción pierde calidad y precisión cuanto menor sea el contacto entre el traductor y el texto. Esto no implica necesariamente que se hayan cometido errores -según Amparo Hurtado Albir es una "equivalencia de traducción inadecuada" (2001: 636)-, sino que el producto es de evidente mejor calidad cuando más tiempo de contacto haya tenido el traductor con el texto de partida.

En el caso del "Documento 001", el traductor contó con tiempo suficiente para realizar la documentación que debe preceder a cualquier traducción escrita. En el caso del "Documento 002", el traductor recibió el texto media hora antes de comenzar a realizar la traducción oral del mismo; este intervalo de media hora fue utilizado por el traductor para preparar el texto buscando términos, analizando estructuras, etc. El "Documento 003" 
fue traducido por el traductor a vista, sin haber tenido exposición previa al mismo. Los tres traductores cuentan con una amplia experiencia en la traducción escrita y oral de este tipo de textos.

\subsection{Estructuras sintácticas}

Del análisis sintáctico del texto original, se desprende la utilización en español de oraciones de gran extensión, en las que se insertan numerosas proposiciones subordinadas, mientras que la estructura sintáctica del idioma meta es mucho más corta y concisa. Por ello, observamos que al traducir por escrito algunas estructuras se simplificaron, o incluso se fragmentaron en varias oraciones. En cambio, cuanto menos acercamiento tuvieron los sujetos al texto de partida (Documentos 002 y 003) más similitud presentan las estructuras de ambos textos. Veámoslo a través de los siguientes fragmentos:

Original: Inicialmente, surgió una discusión entre ellos con motivo del consumo de la droga, que derivó en una reyerta, acometiéndose mutuamente entre sí, utilizando una navaja de unos $12 \mathrm{~cm}$ de hoja, de tal manera que Santiago propinó una puñalada a Gabino en la pierna izquierda con lesión de estructuras vasculares y nerviosas, así como una puñalada en el glúteo derecho, que no afectaron a órganos vitales, precisando tratamiento médico-quirúrgico y transfusión sanguínea $[\ldots]$

Documento 001: Initially, an argument broke out around the consumption of the drugs, which led to a brawl; they started to get at each other using a $12 \mathrm{~cm}$ - blade knife. Santiago stabbed Gabino on his left leg injuring vascular and nerve structures; he also stabbed him on his right gluteus. No injury to the vital organs was caused but he needed medical-surgical treatment and blood transfusions [...]

Documento 002: Initially, an argument broke out over the consumption of the drug, that led to a fight and they started to get at each other using a knife that was or that had a $12 \mathrm{~cm}$ blade in such a way that Santiago stabbed Gabino in his left leg causing and injury to the vascular and nerve structures, and he also stabbed him on his right gluteus, and vital organs were not affected. He needed medicalsurgical treatment and blood transfusion [...]

Documento 003: First, they argued about the consumption of the drug, that led to a fight getting at each other with knife with a $12 \mathrm{~cm}$ blade so much so that Santiago stabbed Gabino in his left leg with vascular and nerve lesions as well as a stab on his right gluteus, not affecting vital 
organs, needing medical-surgical treatment and blood transfusions [...]

Las dos versiones traducidas oralmente presentan una disposición sintáctica más cercana a la del original, especialmente la del Documento 003.

\subsection{Voz pasiva}

Como sabemos, la voz pasiva se utiliza con mucha más frecuencia en inglés que en español, ya que en el segundo caso se tiende a evitarla a través de la utilización de estructuras como la pasiva refleja, la forma impersonal o la forma activa. Las dos versiones traducidas oralmente presentan un uso menos frecuente de la voz pasiva o una formulación de la estructura pasiva más similar a la original:

Original: Así como una puñalada en el glúteo derecho, que no afectaron a órganos vitales, precisando [...]

Documento 001: He also stabbed him on his right gluteus. No injury to the vital organs was caused [...]

Documento 002: He also stabbed him on his right gluteus and vital organs were not affected $[\ldots]$

Documento 003: As well as a stab on his right gluteus, not affecting vital organs $[\ldots]$

\subsection{Subtraducción}

Se han encontrado ejemplos de subtraducción o simplificación de frases nominales 0 adverbiales en las dos versiones orales; más se simplifica y subtraduce cuanto menos es el acercamiento del traductor al texto.

Original: Debemos condenar y condenamos a Santiago, como autor penalmente responsable de dos delitos de lesiones con uso de arma, ya definidos, con la concurrencia de la atenuante de drogadicción, a la pena de dos años de prisión e inhabilitación especial para el derecho de sufragio pasivo durante el tiempo de la condena.

Documento 001: We find Santiago a criminally liable perpetrator of two crimes of injuries with the use of weapons, defined herein above, with the concurrence of the mitigating circumstance of drug addiction; and we sentence him to two years' imprisonment and specific 
disqualification from exercising the right to passive suffrage during the term of his sentence.

Documento 002: We convict Santiago as criminally liable perpetrator of two crimes of injuries with the use of a weapon, already defined, with the concurrence of the mitigating circumstance of drug addiction to two years in prison and special prohibition to exercise his right to passive suffrage during the term of the sentence.

Documento 003: We must convict Santiago as author of two crimes of injuries with the use of weapon, already defined, with the concurrence of the mitigating circumstance of drug addiction to two years in prison and special inhabilitation to vote during the term of the sentence.

\subsection{Nombres de las leyes}

Ante la traducción del nombre de leyes, considero adecuado traducir el nombre de la ley y pronunciarla también, aunque sea una vez, en el idioma original para que quede registrado su nombre original y el sistema jurídico al que pertenece, en este caso el español.

En el corpus empleado, el nombre de las leyes aparece perfectamente traducido en el texto escrito, no así en las versiones traducidas oralmente. Por añadidura, en las versiones orales no se hace referencia a la misma ley de igual manera en cada ocasión en que es traducida.

Original: Ley de Enjuiciamiento Criminal.

Documento 001: FIRST. - Infringement of the law, pursuant to article 849. $1^{\circ}$ and $2^{\circ}$ of the Law on Criminal Prosecution (Ley de Enjuiciamiento Penal), for failure to consider the exonerating circumstance of legitimate defense, or in a subsidiary manner, the equivalent mitigating circumstance. SECOND. - Infringement of the Law, pursuant to article $849.1^{\circ}$ and $2^{\circ}$ of the Law on Criminal Prosecution for misappreciation [...]

Documento 002: FIRST. - For infringement of the law, in virtue of article 849. $1^{\text {o }}$ of the Law of Criminal Prosecution. FIRST. - For infringement of the Constitutional principle or precept, specifically fundamental rights to due process and presumption of innocence provided for under Article 24, second paragraph of the Constitution, and articles $5.4^{\circ}$ paragraph of the LOPJ and 852 of the Criminal Prosecution Law [...] 
Documento 003: SECOND.- For violation of article 849. $1^{\circ}$ and $2^{\circ}$ of the Law on Criminal Prosecution for error in appreciating the evidence. THIRD. - For breaking formalities, in virtue of article $8501^{\circ}$ and $8511^{\circ}$ 응 of the Criminal Prosecution Law for the denial to accept the evidence [...]

\subsection{Nombres de instituciones y órganos jurisdiccionales}

Dado que los sistemas jurídicos del inglés y el español no son equivalentes, se presenta la dificultad de tener que lidiar con la traducción de nombres de instituciones y órganos jurisdiccionales; una de las posibles soluciones es optar por la traducción literal del término y por mantener el nombre original del órgano o institución. El nombre de las instituciones y órganos jurisdiccionales aparece correctamente traducido en el texto escrito, no así en las versiones traducidas oralmente:

Original: Audiencia de Instancia

Documento 001: The Audiencia de instancia [First instance Court]

Documento 002: The Audiencia de Instancia (no se suministró traducción)

Documento 003: The Audiencia de instancia (no se suministró traducción)

\subsection{Repeticiones y reformulaciones}

El sujeto que tuvo acceso al texto objeto de traducción no evidencia repeticiones ni reformulaciones, sin embargo, los dos traductores, especialmente el del Documento 003, hace uso de este tipo de fenómenos con más frecuencia. Por medio de los siguientes ejemplos, se puede observar la profusa repetición de palabras vacías y reformulaciones al principio de las oraciones

Documento 002: FIRST. - For infringement of the Constitutional principle or precept [...] one day and 59 without, or 59 with [...]

Documento 003: THIRD. - For breaking the forms, formalities [...] 


\subsection{Omisiones}

No se han detectado omisiones en el texto escrito, no obstante, los autores de la traducción del Documento 002 y del Documento 003, lógicamente por la celeridad del discurso, omiten información relevante del texto original:

Original: Gabino, mayor de edad y condenado en sentencia firme de 16 de octubre de 2001 [...]

Documento 001: Gabino -of age, convicted by a judgment which has the force of res judicata [...]

Documento 002: Gabino -of age, convicted by firm sentence [...]

Documento 003: Gabino -of age, convicted on September 16, 2001 [...]

\section{CONCLUSIONES}

Facilitar el texto al traductor de textos jurídicos con anterioridad para que este pueda realizar la preparación del texto, de acuerdo con los resultados desprendidos de mi estudio, mejora la calidad de la traducción oral. Tener acceso a un texto y prepararlo antes de realizar la traducción oral del mismo permite que se fijen estructuras en la memoria y que se desarrolle la anticipación.

Por lo tanto, concluyo, que cuando el tribunal suministra el texto por adelantado a los traductores jurados, estos últimos pueden leer las oraciones y preparar su segmentación mentalmente utilizando la técnica de traducción a vista. Pueden, asimismo, insertar guiones, escribir la traducción de términos complicados, etc., y realizar cualquier anotación que les ayude a realizar su labor traductológica. Cuando se puede preparar el texto, el esfuerzo se ve considerablemente reducido, y, consecuentemente, la calidad del texto se verá incrementada significativamente.

\section{REFERENCIAS BIBLIOGRÁFICAS}

Constitución Española de 1978. Disponible en:

http://www.boe.es/legislacion/enlaces/constitucion.php [Consultado el 20 de septiembre de 2013]

DAVID, René, Los grandes sistemas jurídicos contemporáneos (trad. Pedro Bravo Gala). Madrid: Aguilar, 1968.

HURTADO AlBIR, Amparo, Traducción y Traductología: Introducción a la traductología. Madrid: Ediciones Cátedra, 2001. 
Ley de la República Argentina. Ley 20.305 BS. AS 24/4/73. Disponible en: http://www.tradulex.com/Regles/LeyARGENTINA.htm [Consultado el 12 de septiembre de 2013]

Sentencia $n^{\circ}$ 1183/2010 de Tribunal Supremo, Sala $2^{\circ}$, de lo Penal, 27 de diciembre de 2010. Disponible en: http://supremo.vlex.es/vid/252334758 [Consultado el 15 de septiembre de 2013]

ZWEIGERT Konrad; KÖTZ Hein, Introducción al derecho comparado (trad. Arturo Aparicio Vázquez. México: Oxford University Press, 2002. 